\title{
ON THE VARIATION OF THE DISCRETE MAXIMAL OPERATOR
}

\section{FENG LIU}

Abstract. In this note we study the endpoint regularity properties of the discrete nontangential fractional maximal operator

$$
M_{\alpha, \beta} f(n)=\sup _{\substack{r \in \mathbb{N} \\|m-n| \leqslant \beta r}} \frac{1}{(2 r+1)^{1-\alpha}} \sum_{k=-r}^{r}|f(m+k)|,
$$

where $\alpha \in[0,1), \beta \in[0, \infty)$ and $\mathbb{N}=\{0,1,2, \ldots$,$\} , covering the discrete centered Hardy-$ Littlewood maximal operator and its fractional variant. More precisely, we establish the sharp boundedness and continuity for $M_{\alpha, \beta}$ from $\ell^{1}(\mathbb{Z})$ to $\mathrm{BV}(\mathbb{Z})$. When $\alpha=0$, we prove that the operator $M_{\alpha, \beta}$ is bounded and continuous on $\mathrm{BV}(\mathbb{Z})$. Here $\mathrm{BV}(\mathbb{Z})$ denotes the set of functions of bounded variation defined on $\mathbb{Z}$. Our main results represent generalizations as well as natural extensions of many previously known ones.

Mathematics subject classification (2010): 42B25, 46E35.

Keywords and phrases: Discrete nontangential fractional maximal operator, bounded variation, boundedness, continuity.

\section{REFERENCES}

[1] J. M. Aldaz And J. PÉrez LÁZARo, Functions of bounded variation, the derivative of the one dimensional maximal function, and applications to inequalities, Trans. Amer. Math. Soc., 359, 5 (2007), 2443-2461.

[2] J. Bober, E. Carneiro, K. Hughes, D. Kosz and L. B. Pierce, Corrigendum to "On a discrete version of Tanaka's theorem for maximal functions”, Proc. Amer. Math. Soc., 143, 12 (2015), 54715473.

[3] J. Bober, E. Carneiro, K. Hughes And L. B. Pierce, On a discrete version of Tanaka's theorem for maximal functions, Proc. Amer. Math. Soc., 140, 5 (2012), 1669-1680.

[4] E. Carneiro And K. Hughes, On the endpoint regularity of discrete maximal operators, Math. Res. Lett., 19, 6 (2012), 1245-1262.

[5] E. CARneIRo And J. MAdRID, Derivative bounds for fractional maximal functions, Trans. Amer. Math. Soc., 369, 6 (2017), 4063-4092.

[6] E. Carneiro, J. Mardid And L. B. Pierce, Endpoint Sobolev and BV continuity for maximal operators, J. Funct. Anal., 273, 10 (2017), 3262-3294.

[7] E. Carneiro And D. Moreira, On the regularity of maximal operators, Proc. Amer. Math. Soc., 136, 12 (2008), 4395-4404.

[8] E. CARNeIRo AND B. F. Svaiter, On the variation of maximal operators of convolution type, J. Funct. Anal., 265, 5 (2013), 837-865.

[9] P. HaJŁasZ AND J. MaLÝ, On approximate differentiability of the maximal function, Proc. Amer. Math. Soc., 138, 1 (2010), 165-174.

[10] P. HajŁasZ And J. OnNinen, On boundedness of maximal functions in Sobolev spaces, Ann. Acad. Sci. Fenn. Math., 29, (2004), 167-176.

[11] J. Kinnunen, The Hardy-Littlewood maximal function of a Sobolev function, Israel J. Math., 100, (1997), 117-124.

[12] J. Kinnunen And P. Lindqvist, The derivative of the maximal function, J. Reine Angew. Math., 503, (1998), 161-167. 
[13] J. Kinnunen And E. Saksman, Regularity of the fractional maximal function, Bull. London Math. Soc., 35, (2003), 529-535.

[14] O. KurKa, On the variation of the Hardy-Littlewood maximal function, Ann. Acad. Sci. Fenn. Math., 40, (2015), 109-133.

[15] F. LiU, A remark on the regularity of the discrete maximal operator, Bull. Austral. Math. Soc., 95, (2017), 108-120.

[16] F. LIU, Continuity and approximate differentiability of multisublinear fractional maximal functions, Math. Inequal. Appl., 21, 1 (2018), 25-40.

[17] F. LIU, On the regularity of one-sided fractional maximal functions, Math. Slovaca, 68, 5 (2018), 1097-1112.

[18] F. LiU, T. Chen AND H. Wu, A note on the end-point regularity of the Hardy-Littlewood maximal functions, Bull. Austral. Math. Soc., 94, (2016), 121-130.

[19] F. LiU AND S. MAO, On the regularity of the one-sided Hardy-Littlewood maximal functions, Czech. Math. J., 67, 142 (2017), 219-234.

[20] F. LIU AND H. WU, On the regularity of the multisublinear maximal functions, Canad. Math. Bull., 58, 4 (2015), 808-817.

[21] F. LIU AND H. WU, Endpoint regularity of multisublinear fractional maximal functions, Canad. Math. Bull., 60, 3 (2017), 586-603.

[22] F. LiU AND H. Wu, Regularity of discrete multisublinear fractional maximal functions, Sci. China Math., 60, 8 (2017), 1461-1476.

[23] F. LiU AND H. WU, On the regularity of maximal operators supported by submanifolds, J. Math. Anal. Appl., 453, (2017), 144-158.

[24] F. LiU AND H. Wu, A note on the endpoint regularity of the discrete maximal operator, Proc. Amer. Math. Soc., 147, 2 (2019), 583-596.

[25] H. Luiro, Continuity of the maixmal operator in Sobolev spaces, Proc. Amer. Math. Soc., 135, 1 (2007), 243-251.

[26] H. LuIRO, On the regularity of the Hardy-Littlewood maximal operator on subdomains of $\mathbb{R}^{n}$, Proc. Edinburgh Math. Soc., (2) 53, 1 (2010), 211-237.

[27] H. LUIRO, The variation of the maximal function of a radial function, 56, 1 (2018), 147-161.

[28] J. MADRID, Sharp inequalities for the variation of the discrete maximal function, Bull. Austral. Math. Soc., 95, 1 (2017), 94-107.

[29] J. MADRID, Endpoint Sobolev and BV continuity for maximal opertors, II, preprint at http://arXiv: 1710.03546v1.

[30] J. P. G. Ramos, Sharp total variation results for maximal functions, Ann. Acade. Sci. Fenn. Math., 44, (2019), 41-64.

[31] H. TANAKA, A remark on the derivative of the one-dimensional Hardy-Littlewood maximal function, Bull. Austral. Math. Soc., 65, 2 (2002), 253-258.

[32] F. TEMUR, On regularity of the discrete Hardy-Littlewood maximal function, preprint at http://arxiv.org/abs/1303.3993. 